5. Executive Summary: Merging Quality Science with Supplement Research. NIH Publication No. 99-4365. Office of Dietary Supplements, Office of the Director, September, 1998.

6. Fugh-Berman A. Herb-Drug Interactions: A Review. The Lancet 2000;355:134-138.

7. Huang OL, Lewin NA, Howland, MA. Herbal Preparations. Chapt. 76 In: Goldfrank's Toxicologic Emergencies, 6th Edition. Appleton Lange, Stamford, CN, 1998; pp 121-42.

8. Kassler WJ, Blanc P, Greenblatt R. The Use of Medicinal Herbs by Human Immunodeficiency Virus-Infected Patients. Arch Int Med 1991;151:2281-2288.

9. Levitt J. Letter and Outline on Dietary Supplement Strategy. Ten Year Plan. Center for Food Safety and Applied Nutrition (CFSAN), Food and Drug Administration, January, 2000.

10. The Complete German Commission E Monographs:
Therapeutic Guide to Herbal Medicines. (Official English translation) American Botanical Council, Austin, TX, 1998.

11. Tsen LC, Segal S, Pothier M, Bader AM. Alternative Medicine Use in Presurgical Patients. Anesthesiology 2000; 93:148-151.

12. Tyler V. The Honest Herbal. Pharmaceutical Products Press, Binghampton, NY, 1993.

13. Weiss RF, Fintelmann V. Herbal Medicine, 2nd Edition. Thieme, Stuttgart \& NY, 2000.

\section{WEBLINKS}

MEDLINEplus "Herbal Medicine" website is a list of links, including to the NCCAM (National Center for Complementary and Alternative Medicine) at NIH, a Pandora's box of information in itself.

\title{
ACMT Position Statement: Institutions Housing Venomous Animals
}

\author{
Steven A. Seifert, MD, FACMT, FACEP, Chair, Dan Keyler, PharmD, Geoff Isbister, BSc MBBS, \\ Jude McNally, RPh, ABAT, Thomas G. Martin, MD, MPH, ACMT Board Liaison
}

REPRINTED FROM WWW.ACMT.NET

\section{BACKGROUND}

There are no published standards regarding the responsibilities of institutions housing venomous animals. Manifestations and management of the envenomations of non-native venomous animals are unfamiliar to most potential local treating physicians. Proper planning for such envenomations includes proper storage, transport and use of non-licensed antivenoms, Emergency Medical System coordination, receiving medical facility coordination, regional poison center involvement and the involvement of an appropriately trained or experienced clinician. Therefore: When an institution houses, displays or otherwise has possession of venomous animals, it is incumbent upon that institution to assure that the likelihood of human envenomation is minimized and that there is a written plan to respond to any envenomation that may occur.

1. Acquisition and Housing: Venomous animals with significant envenomation risks should only be acquired and maintained by institutions that have the resources and capabilities to properly care for them and where the regional resources and capabilities exist to manage envenomations. Venomous animals should be housed and displayed in properly designed enclosures.

2. Antivenom Acquisition: When antivenom is available, it should be obtained prior to the institution's acquisition of the venomous animal. When an FDA approved species-specific antivenom is available, the institution should procure an amount adequate to treat a moderately to severely envenomated victim. When FDA approved antivenom is not available, an antivenom that is approved for use in another country is preferred over antivenom with no governmental regulatory approval. Decisions regarding which antivenom to obtain and in what amounts should be made by the physician or clinical toxicologist identified below. When only non-FDA approved species-specific antivenom(s) are available, it is the responsibility of the institution to obtain an importation permit and FDA investigational new drug (IND) application for appropriate antivenom. Replacement antivenom should be obtained prior to expiration of old stock. 
3. Antivenom Storage: Antivenom may be stored at the institution where the venomous animal is housed or at the intended medical receiving facility. If the antivenom is to be stored at the institution, storage conditions should meet manufacturer's recommendations and standards of hospital pharmacy storage (i.e. refrigeration with back-up power supply, temperature monitoring, and expiration date surveillance).

4. Venomous Animal Handling and Identification: Written procedures regarding staff training, venomous animal handling, and feeding should be created to minimize envenomation risk. Procedures should be in place to assure accurate identification of potentially envenomating animals.

5. Consultations: A clinical toxicologist or a physician knowledgeable and experienced in the management of envenomations should be responsible for the policies and procedures regarding first aid and ongoing medical management of envenomations. At the medical receiving facility, victims of envenomation should be treated or managed in consultation with clinical toxicologists or physicians with expertise defined above.

6. Poison Center Collaboration: Collaboration with the nearest AAPCC-certified regional poison center should occur during the process of medical response planning.

7. Patient Transport and Treatment Plan: A preexisting written agreement should be in place with emergency medical transport agencies and a receiving medical facility. There should be a written plan for timely and appropriate first aid to be administered to an envenomated individual and timely evacuation and transport of the victim (and antivenom if stored at the institution) to the designated medical receiving facility. A copy of mutuallyagreed upon (institution and medical receiving facility) management guidelines, including preparation and use of any antivenom, should accompany the patient.

8. Medical Receiving Facility: The institution should designate a medical receiving facility to receive victims of envenomation. The facility should have the capability to properly care for any possible adverse reactions to envenomation or treatment with antivenom. The receiving facility should have written policies and procedures for patient assessment and management of envenomations, for appropriate antivenom receipt (if sent with the patient), storage, preparation and administration. Because of the extensive and specialized preparations and skills required in the management of envenomations, the medical receiving facility should have policies in place to accept envenomation victims regardless of the facility's diversion status.

9. IRB Approval: If non-FDA-approved antivenoms are intended for use, investigational review board (IRB) approval for emergency use must be obtained at the medical receiving facility.

10. Antivenom Index Participation: It is encouraged that any institution that procures non FDA approved antivenom be listed in the Antivenom Index,1 (published by the American Zoo and Aquarium Association (AZA) and American Association of Poison Control Centers (AAPCC), and which lists common and scientific names, antivenoms effective for various species, participating institutions, antivenom manufacturers and sources, procedures for importing non-licensed antivenoms, emergency procedures and first aid, recommendations for handling of venomous animals and general management of elapid and crotaline envenomations). If an institution consents to the use of its antivenom by another medical facility, replacement or reimbursement is expected.

\section{REFERENCE}

1. Antivenom Index. The American Zoo and Aquarium Association and The American Association of Poison Control Centers. Donal M. Boyer Ed. San Diego, 1999. 